INFORME DE CASO

\title{
Exantema asociado a COVID-19
}

\author{
Recibido: 28/10/20 Aceptado: 24/11/20
}

Patricia Analía Fernández Pardal', Viviana Leiro', Yasmin Nicole Alvaro', Camila Iglesias Leal', María del Valle Rueda' ${ }^{1}$ Carola Villanueva Bruce ${ }^{1}$, Esteban Maronna², Lilia Mammana ${ }^{3}$, José Ignacio Carranza ${ }^{4}$, Liliana María Olivares ${ }^{1}$.

\section{RESUMEN}

A partir de marzo de 2020 se han empezado a describir lesiones cutáneas asociadas a COVID-19 que fueron agrupadas en patrones y se relacionaron con la severidad y la temporalidad de la enfermedad. Se presenta el caso de un paciente con COVID-19 leve y lesiones cutáneas que pueden atribuirse a la infección. Se realiza una revisión de las manifestaciones cutáneas asociadas a COVID-19 y la interpretación de los diagnósticos diferenciales que se pensaron en el paciente.

Palabras clave: COVID-19, SARS-CoV-2, exantema.
1 Unidad de Dermatología, Hospital Francisco Javier Muñiz, CABA, Argentina.

2 Servicio de Anatomía Patológica, Hospital Francisco Javier Muñiz, CABA, Argentina.

${ }^{3}$ Unidad de Virología, Hospital Francisco Javier Muñiz, CABA, Argentina.

${ }^{4}$ Sección Zoopatología Médica y Parasitología, Hospital Francisco Javier Muñiz, CABA, Argentina.

Dirección para la correspondencia: Patricia Fernández Pardal. Uspallata 2272, CABA.

Email: patriciafernandezpardal@yahoo.com

Los contenidos del material no han sido publicados anteriormente. No se han recibido ayudas específicas provenientes de agencias del sector público, sector comercial o entidades sin ánimo de lucro. No existe conflicto de interés de ninguno de los autores en relación con la realización de este trabajo. 


\section{Introducción}

La enfermedad por coronavirus-19 (COVID-19) resulta de la infección por el nuevo coronavirus SARS-CoV-2. Su vía de contagio y su compromiso son principalmente respiratorios. El primer caso fue registrado en la ciudad de Wuhan, China, en diciembre de 2019. En marzo de 2020, Recalcati (1) describió el desarrollo de exantemas en individuos con COVID-19 que no tenían antecedentes de ingesta de fármacos. Posteriormente se han publicado numerosos trabajos que clasificaron las lesiones cutáneas de pacientes con COVID-19 en patrones según la lesión elemental, establecieron una relación entre dicho patrón y la gravedad de la enfermedad, estudiaron su correlación histopatológica y evaluaron su inclusión entre los criterios de diagnóstico de COVID-19.

Se presenta el caso de un paciente con COVID-19 y exantema.

\section{Caso clínico}

Un hombre de 24 años de edad concurrió en septiembre de 2020 al departamento de urgencias por fiebre (38 grados) intermitente de seis días de evolución y anosmia y exantema de tres días de evolución. Había tenido una relación sexual sin protección cuatro días previos al inicio de los síntomas, por lo cual inició profilaxis post exposición (PPE) para HIV con zidovudina, lamivudina, lopinavir y ritonavir. El paciente no refería otros antecedentes clínicos significativos. Al ingreso se encontraba afebril, hemodinámicamente estable y sin requerimiento de oxígeno. Al examen físico presentaba exantema maculopapuloso en sectores confluentes. El mismo se había iniciado en antebrazo derecho, con progresión a región lateral derecha del tórax, y luego al lado contralateral y raíz de muslos (Figura 1). No presentaba compromiso palmoplantar ni de mucosas, ni adenomegalias generalizadas. El exantema era moderadamente pruriginoso a predominio nocturno.

El examen de laboratorio de rutina no mostró datos relevantes. El estudio de PCR de hisopado nasal detectó SARS-CoV-2. Se realizó el siguiente panel de anticuerpos: HIV de cuarta generación a los 5 y 50 días de la relación sexual sin protección, anti core hepatitis $\mathrm{B}$, antígeno y anticuerpo de superficie para hepatitis $B$, anticuerpos totales para hepatitis $C$, lgM e lg $\mathrm{G}$ para hepatitis $A$ y prueba treponémica para síflis con resultado no reactivo. La serología IgG para sarampión, parvovirus B19, Echovirus, antígeno de la cápside viral y antígeno nuclear de virus de Epstein Barr, rubéola y citomegalovirus fueron reactivos (con IgM no reactivas). La radiografía de tórax no evidenció lesiones. Biopsia de piel, de muslo izquierdo: epidermis con ortoqueratosis y dermis con leve infiltrado linfocitario perivascular superficial (Figura 2).

Se continuó tratamiento con zidovudina, lamivudina, lopinavir y ritonavir. Se indicó difenhidramina $50 \mathrm{mg}$ por el prurito con resolución del exantema a los 7 días.

\section{Discusión}

El SARS-CoV-2 es un virus ARN que ingresa a la célula a través del receptor tipo 2 de la enzima convertidora de angiotensina. Este receptor se encuentra en las células alveolares del pulmón y en diferentes órganos, incluido la piel. Se han propuesto varias etiologías para el desarrollo de las lesiones cutáneas inducidas por el virus, como el desarrollo de vasculitis a nivel de los capilares de la piel, el efecto citopático viral, la respuesta inflamatoria y alteraciones en la coagulación (2).

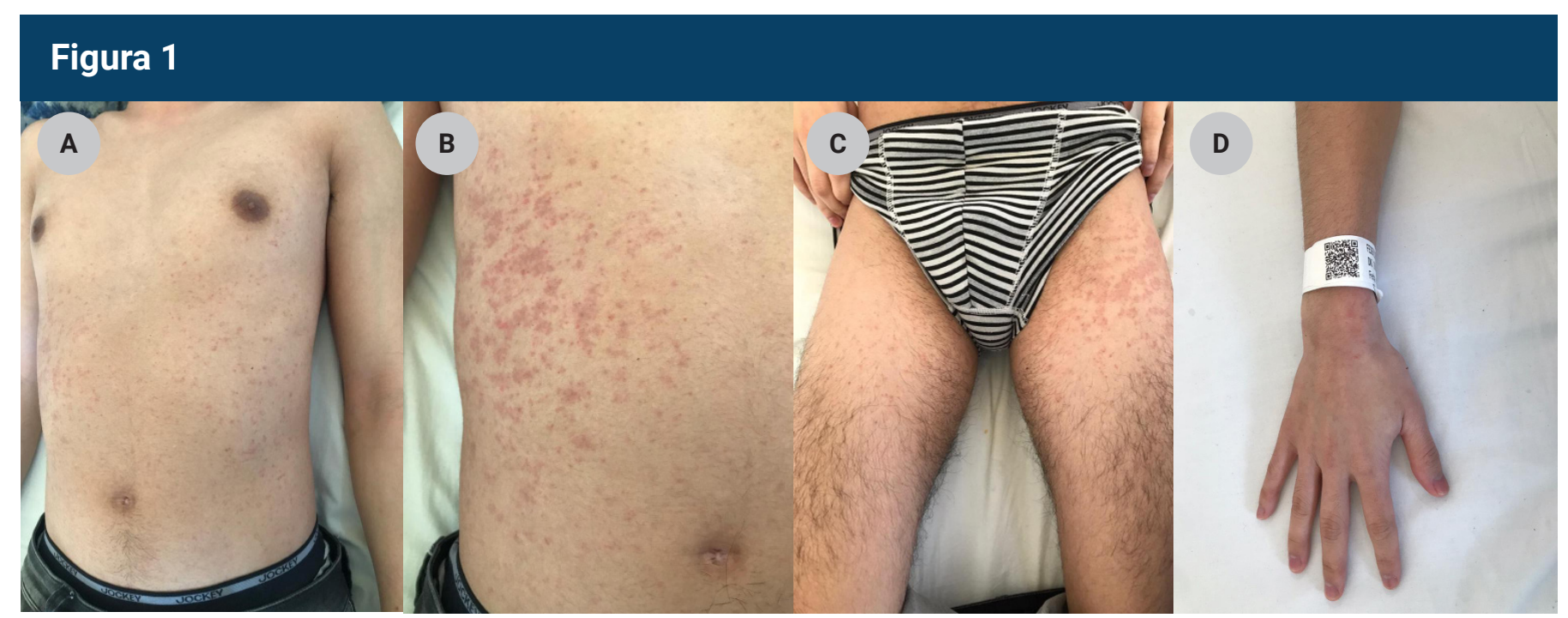

Exantema maculopapuloso en tronco (A) con predominio en región lateral (B) y en raíz de miembros inferiores (C). Lesiones en antebrazo derecho (D). 


\section{Figura 2}

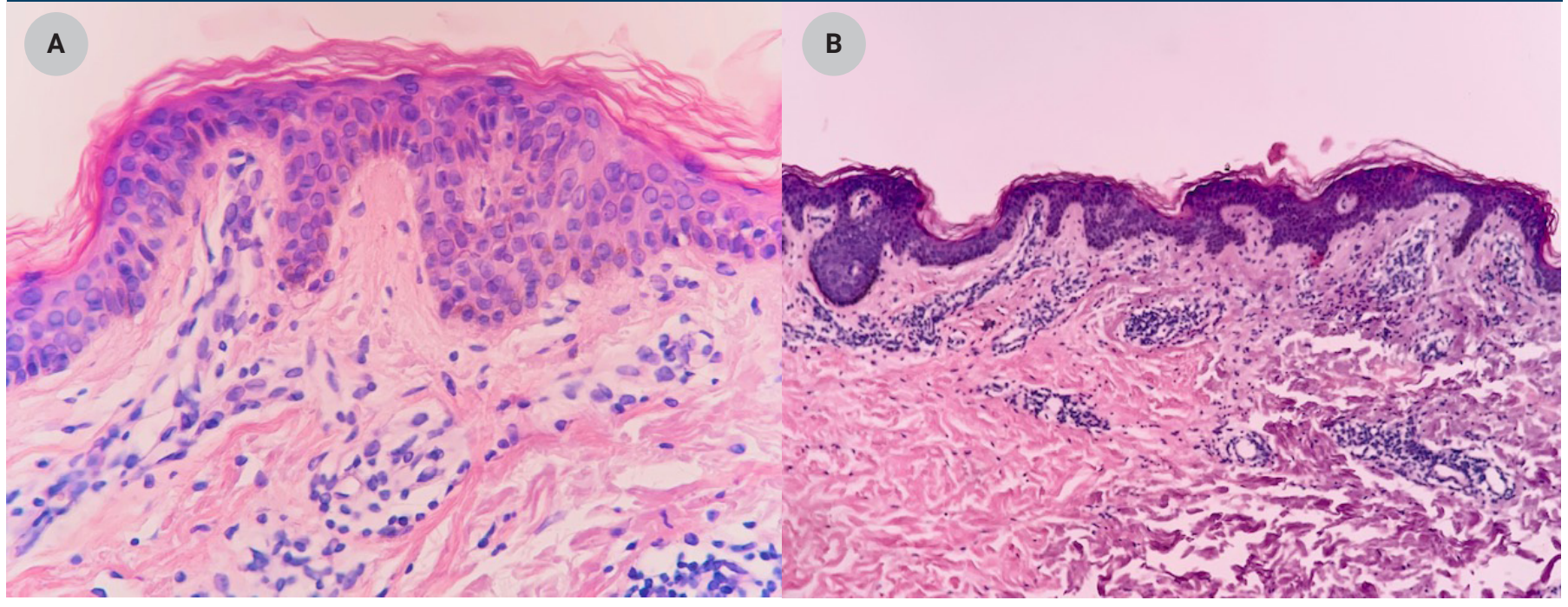

A. Hematoxilina-eosina 100 aumentos: epidermis con ortoqueratosis. Dermis con moderado infiltrado linfocitario perivascular. B. Hematoxilina-eosina 400 aumentos: Infiltrado perivascular superficial constituido por linfocitos pequeños.

La frecuencia de lesiones cutáneas atribuibles al COVID-19 es muy variable según la literatura, entre 0,2 y $20,4 \%$ (3). Uno de los motivos que explicaría esta disparidad es que sin una evaluación de rutina por el especialista las manifestaciones cutáneas podrían no ser percibidas por el paciente ni por los profesionales del equipo de salud.

Han surgido varias clasificaciones de las lesiones cutáneas asociadas a COVID-19 (Tabla 1). La primera fue realizada por Catalá G. A. y Galván Casas C., que las clasificaron en cinco patrones: 1) pseudoperniosis, 2) vesiculoso, 3) urticariforme, 4) maculopapular y 5) livedo/necrosis (4). La frecuencia hallada de los distintos patrones fue variable en los diferentes estudios (Tabla 1).
Varios autores notaron una relación temporal de algunos patrones con el curso de la enfermedad. Las erupciones vesiculosas suelen aparecer en las primeras etapas, mientras que el patrón de pseudoperniosis es tardío. En forma coincidente, estos dos patrones fueron los más característicos de COVID-19 (4). Sin embargo, en posteriores series de casos de pacientes con perniosis no se pudo confirmar la relación del cuadro dermatológico con una infección actual o previa por SARS-CoV-2 (5).

El exantema maculopapuloso morbiliforme es la presentación más frecuente en algunas series (hasta el $47 \%)(4,6)$ y suele aparecer junto a los otros síntomas de la enfermedad y persistir por 3 a 10 días. La asociación con prurito es variable, e incluso en algunas series no está aclarado este síntoma (3,

\section{Tabla 1. Patrones cutáneos asociados a COVID-19}

\begin{tabular}{|c|c|c|c|c|}
\hline \multicolumn{2}{|c|}{ Trabajo } & $\begin{array}{l}\text { Galvan Casas (4) } \\
\text { (abril 2020) }\end{array}$ & $\begin{array}{c}\text { Freeman (6) } \\
\text { (abril-mayo 2020) }\end{array}$ & $\begin{array}{c}\text { Daneshgara (7) } \\
\text { (mayo 2020) }\end{array}$ \\
\hline \multicolumn{2}{|c|}{ Tipo de estudio } & Serie de casos & Serie de casos & Revisión \\
\hline \multicolumn{2}{|c|}{ Número de pacientes } & 375 & 716 & 996 \\
\hline \multirow{8}{*}{ Patrón } & Pseudoperniosis & $19 \%$ & $18 \%$ & $40,4 \%$ \\
\hline & Vesiculoso & $9 \%$ & $11 \%$ & $13 \%$ \\
\hline & Urticariforme & $19 \%$ & $16 \%$ & $10,9 \%$ \\
\hline & Maculo-papular/ morbiliforme & $47 \%$ & $22 \%$ & $21,3 \%$ \\
\hline & Livedo/necrosis & $6 \%$ & $6,4 \%$ & $4 \%$ \\
\hline & Maculoso & - & $13 \%$ & - \\
\hline & Papulo-escamoso & - & $9,9 \%$ & - \\
\hline & Símil eritema multiforme & - & - & $3,7 \%$ \\
\hline
\end{tabular}


4, 6). La distribución perifolicular, la acentuación en pliegues y las lesiones eritematoescamosas fueron descriptas ocasionalmente (3).

También se han relacionado ciertos patrones cutáneos con la severidad de la infección por COVID-19. El eritema pernio se encontró en pacientes levemente enfermos, de los cuales solo el $16 \%$ requirió internación $(4,6)$. En orden creciente de severidad se ubicó el patrón vesicular, urticariforme, maculoso y maculopapuloso. $Y$ en el extremo de mayor severidad, la púrpura retiforme, con el $100 \%$ de ellos hospitalizados y el $80 \%$ con síndrome de distrés respiratorio (6). El síndrome de inflamación multisistémica asociado a COVID-19, símil enfermedad de Kawasaki, se observa en individuos con mal estado general y compromiso visceral, y que a nivel de piel presentan eritema difuso o lesiones símil eritema multiforme, edema acral y compromiso de mucosa oral $(7,8)$.

Los hallazgos histopatológicos son inespecíficos, al igual que gran parte de los exantemas producidos por otros virus. En la mayoría de los patrones clínicos se encuentran infiltrados linfocitarios perivasculares. También se puede observar dermatitis de interfase vacuolar con grados variables de espongiosis, que se superpondría con los hallazgos histopatológicos de pacientes con exantemas de causa farmacológica. Además se han descripto, en las pseudoperniosis y lesiones urticariformes, edema en dermis, y en los patrones livedoides y necróticos, vasculopatía necrótica. En el patrón vesicular se han encontrado vesículas intraepidérmicas con queratinocitos balonizados y multinucleados y acantolisis focal, semejante a lo observado en las lesiones de manos, pies y boca $(3,6)$.

El compromiso cutáneo en la infección por COVID-19 no sería útil para sospechar su diagnóstico. Esto se debe a la inespecificidad de su semiología y a los diversos diagnósticos diferenciales que se plantean con otras virosis e incluso con farmacodermias (4).

En el paciente presentado se evaluaron como posibles causas del exantema: síndrome retroviral agudo en el contexto de una infección primaria por HIV, reacción cutánea adversa a fármacos, exantema asociado a COVID-19 o a otras virosis concomitantes.

El síndrome retroviral agudo en individuos con infección primaria por HIV se manifiesta con exantema morbiliforme, urticariforme o roseoliforme, en general no pruriginoso, y con lesiones aftoides en mucosa oral y genital, acompañado de síndrome pseudogripal y molestias gastrointestinales (9).
La serología para HIV de cuarta generación realizada en el paciente fue negativa, la misma detecta anticuerpos para HIV 1 y 2 y antígeno.

Una de las mayores dificultades diagnósticas se plantea con las farmacodermias, en particular con los antirretrovirales (10). En este paciente, alejan este diagnóstico: la falta de compromiso sistémico (fiebre, movilización de enzimas hepáticas, adenomegalias, etc.), la ausencia de signos histopatológicos sugestivos y la resolución espontánea a los pocos días, a pesar del mantenimiento de los fármacos sospechosos.

Se ha observado que pacientes con COVID-19 pueden presentar reactivación de los virus de la familia del herpes (11). El panel de anticuerpos para descartar otras virosis acompañantes no arrojó resultados compatibles con infección aguda o reactivación.

Los pacientes con COVID-19 también pueden presentar coinfección con dengue, y este a su vez asociarse a manifestaciones cutáneas. Sin embargo, en esos meses no había registro de casos de dengue en la región, el paciente no tenía antecedentes de viajes, ni tampoco tenía alteraciones en el hemograma y el hepatograma.

Dada la detección de SARS-CoV-2 en el estudio de PCR no se realizaron estudios para evaluar otras infecciones respiratorias (12).

Enestepacientese interpretó el exantema como probablemente asociado a COVID-19, con un patrón laterotorácico unilateral. El mismo se caracteriza por pápulas eritematosas que pueden confluir, se inicia en forma unilateral en tórax afectando el pliegue axilar, y se extiende a tronco y lado contralateral en el transcurso de los días. El prurito es variable. Esta modalidad de exantema se la ha vinculado a diferentes virus (adenovirus, parainfluenza, parvovirus B19, VHH-6, VHH-7, VEB y Echovirus) y recientemente a COVID-19 (8).

\section{Conclusión}

Las lesiones cutáneas se pueden asociar al COVID-19, es por ello que se sugiere inspeccionar la piel en forma rutinaria en estos individuos. Su aparición plantea otros diagnósticos diferenciales como reacciones cutáneas adversas a fármacos e infecciones concomitantes. Si bien no constituyen un criterio para el diagnóstico de la enfermedad, su observación y descripción permitirán adquirir un mayor conocimiento de las mismas. 


\section{Referencias}

1. Recalcati S. Cutaneous manifestations in COVID-19: a first perspective. J Eur Acad Dermatol Venereol. 2020 May;34(5):e212-e213. doi: 10.1111/jdv.16387. PMID: 32215952.

2. Gottlieb M, Long B. Dermatologic manifestations and complications of COVID-19. Am J Emerg Med. 2020 Sep;38(9):1715-1721. doi: 10.1016/j. ajem.2020.06.011. Epub 2020 Jun 6. PMID:32731141; PMCID: PMC7274995.

3. P, Plaserico S, Bordin C, Alaibac M, Girolomoni G, et al. Cutaneous manifestations of SARS-CoV-2 infection: a clinical update. J Eur Acad Dermatol Venereol. 2020 Jun 25:10.1111/jdv.16774. Epub ahead of print. PMID: 32585074; PMCID:PMC7362144.

4. Galván Casas $C$, Català $A$, Carretero Hernández G, Rodríguez-Jiménez $P$, et al. Classification of the cutaneous manifestations of COVID-19: a rapid prospective nationwide consensus study in Spain with 375 cases. Br J Dermatol. 2020 Jul;183(1):7177. doi: 10.1111/bjd.19163. Epub 2020 Jun 10. PMID: 32348545; PMCID: PMC7267236.

5. Baeck M, Herman A. COVID toes: where do we stand with the current evidence? [published online ahead of print, 2020 Oct 16]. Int J Infect Dis. 2020;102:53-55. doi:10.1016/j.ijid.2020.10.021

6. Freeman EE, McMahon DE, Lipoff JB, Rosenbach $M$, et al. The spectrum of COVID-19-associated dermatologic manifestations: An international registry of 716 patients from 31 countries. J Am Acad Dermatol. 2020 Oct;83(4):1118-1129. doi: 10.1016/j.jaad.2020.06.1016. Epub 2020 Jul 2. PMID: 32622888; PMCID: PMC7331510.

7. Daneshgaran G, Dubin DP, Gould DJ. Cutaneous Manifestations of COVID-19: An Evidence-Based Review. Am J Clin Dermatol. 2020 Oct;21(5):627-639. doi: 10.1007/s40257-020-00558-4. PMID: 32865778; PMCID: PMC7456663.

8. Glick LR, Fogel $A L$, Ramachandran $S$, Barakat LA. Unilateral laterothoracic exanthem in association with coronavirus disease 2019. JAAD Case Rep. 2020 Sep;6(9):900-901. doi: 10.1016/j.jdcr.2020.07.020. Epub 2020 Jul 21. PMID: 32835047; PMCID: PMC7372280.

9. Henn A, Flateau C, Gallien S. Primary HIV Infection: Clinical Presentation, Testing, and Treatment. Curr Infect Dis Rep. 2017 Sep 7;19(10):37. doi: 10.1007/ s11908-017-0588-3. PMID: 28884279.

10. Goiriz, R., \& Herrera, J. F. Toxicodermias en pacientes con síndrome de inmunodeficiencia adquirida. Piel. 2008 23(6), 303-308.

11. Drago, F., Ciccarese, G., Rebora, A., \& Parodi, A. (2020). Human herpesvirus-6, -7, and Epstein-Barr virus reactivation in pityriasis rosea during COVID-19. Journal of medical virology, 10.1002/jmv.26549. Advance online publication. https://doi.org/10.1002/ jmv.26549

12. Kaley J, Pellowski DM, Cheung WL, Hiatt KM. The spectrum of histopathologic findings in cutaneous eruptions associated with influenza $A(\mathrm{H} 1 \mathrm{~N} 1)$ infection. J Cutan Pathol. 2013;40:226-229. 


\section{COVID-19 skin rash}

Since March 2020, skin lesions associated with COVID-19 have begun to be described. These were grouped into patterns, and were related to the severity and temporality of the disease. A patient with mild COVID-19 and skin lesions that can be attributed to the infection is presented. A review of the cutaneous manifestations associated with COVID-19 and the interpretation of the differential diagnoses that were thought of in the patient is carried out.

Keywords: COVID-19, SARS-CoV-2, exanthem. 